\title{
Training, re-training and getting back to practice
}

\author{
J. M. Heath, 1
}

\begin{abstract}
Career breaks occur for many reasons and may well be the pattern for the future. In a recent survey, ${ }^{1}$ reasons given for career breaks included personal and family sickness, childrearing, travelling and study. Childrearing was the most common reason for women to have a break and personal sickness for men. Although these breaks may be short, they may be multiple and therefore have enormous implications for workforce planning.
\end{abstract}

Over the years a number of initiatives have been developed to try and improve the facilities available for those dentists who have, for whatever reason, taken a break from their career. This article is about an exciting new course that is starting in East Anglia, funded by the Department of Health, which has been developed for the whole dental team, not just for dentists.

Historically, a retainer scheme for women dentists was proposed as far back as 1973. In 1979, this was established by the Department of Health, as the Dentists Retainer Scheme. It was re-launched as KITS (Keeping in Touch Scheme) in 1988.

KITS is an excellent scheme for literally 'keeping in touch' with activities and changes within the profession. It is still strongly recommended that anyone (male or female) planning to be away from paid dental employment should join. It pays an allowance towards the cost of staying on the register and a subscription to a dental journal and defence organisation. Another very important advantage is that participants in the scheme get access to all continuing dental education (Section 63) courses and free distance learning materials (CAL Programmes). This is obviously an important point to be considered with regard to re-certification with the GDC.

KITS, however does not provide the comprehensive retraining that might be necessary for someone returning to work after a longer career break, 'Getting Back to Practice Courses' have been organised in different regions throughout the UK to answer this need. Alan Lawrence, who ran the first pilot 'Getting Back to Practice Course' in 1987, found that the average break for those taking part in that and subsequent courses

${ }^{1}$ Janet Heath is Director of Postgraduate Dental Education at the East Anglian Deanery. was 7.3 years.

'Getting back to practice' courses are confidence builders, not only for the participants, but also for future employers and most importantly for patients. Those returning after a few years absence from practice will be confronted not only by new materials and new techniques, but also by new jargon.

It is important that this new jargon is put into practice. Clinical Governance was not even in the dental vocabulary seven years ago, yet this programme of quality improvement, to ensure minimum standards of patient care and encourage good practice, is to be included in the Terms of Service for the General Dental Services, from April 2001. It must therefore, form the foundation of any retraining programme.

As stated earlier, the Department of Health has given funding for an innovative course to be developed for the dental team of the twenty-first century. The new clinical skills room, in the Ipswich Hospital Postgraduate Centre, with its twelve workstations will be the venue for the study days. The course will be residential and (in keeping with the needs of the delegates) creche facilities will be available.

It is important that those returning to work are brought up-to-date and prepared for life-long learning. It is hoped that the course that has been developed at the Postgraduate Centre will attract not only dentists, but also dental therapists and hygienists, who are thinking seriously about returning to work.

The taught part of the course will be used to enhance knowledge and the hands-on, practical elements to enhance skills. The educational components of the course are very much the tip of the iceberg. The group dynamics are very important in building up the confidence necessary for a successful return to work. This element of peer review will enhance attitudes and is very much the 'hidden curriculum'.

A mentor will be available to help, guide and support participants. They will be asked to identify their learning needs, using a professional development portfolio. Follow-up days have been arranged so that the course will be responsive to their needs.

There are only just over 380 dental therapists on 'The Roll of Dental Auxiliaries'. There must however, be many more who have qualified, but are unable to find employment because of the restrictions of working only in the Hospital Dental Service (HDS) or Community Dental Service (CDS). It is to be hoped that there will be new opportunities for dental therapists as part of the Personal Dental Services (PDS).

A flexible, multi-professional work force is the work force of the future, with parttime working and job sharing becoming more commonplace. Participation in this innovative course should prepare these vital members of the dental team for their return to practice

1 Newton J T, Thorogood N, Gibbons D. A study of the career development of male and female dental practitioners. Br Dent J2000; 188: 9094.

\section{Course Dates}

- For Dentists

Monday 2nd April 200I-Friday 6th

April 200I

With follow-up days from Tuesday

8th May-Thursday I0th May 200I

- For Therapists and Hygienists Monday 2nd-Thursday 5th April 200I

With follow-up days in June 200

For details, an information pack and application form contact:

Keith Pearce.

Dental Education Manager,

East Anglian Deanery,

Block 3, Ida Darwin Site,

Fulbourn, Cambridge, CBI 5EE

Tel: $01223884852 / 884850$

Fax: 01223884849

e-mail:

keith.pearce@lifespan-tr.anglox.nhs.uk 